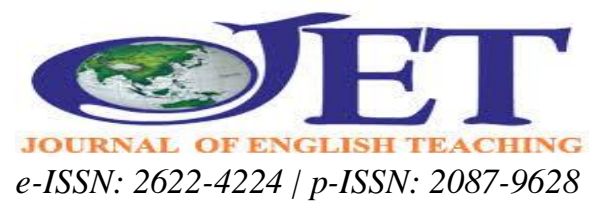

\title{
Making a Difference through Effective Instructional Strategies
}

\author{
Luisito Nanquil \\ luisitonanquil@gmail.com \\ Bulacan State University, Philippines
}

DOI: http://dx.doi.org/10.33541/jet.v5i2.1067

\begin{abstract}
This article depicts the challenges of language teachers (and all teachers) in the delivery of the instruction and evaluation of the learning process. The author expressed his own views and perspectives regarding the present situations confronting language teachers and other teachers of different subjects. While technology provides the things we need in the classroom setting, there are considerable impediments teachers are facing. What could be the roles teachers in the academy have to fulfill and execute so that they can assist diverse learners? This paper discusses and explains imperative thoughts and reflections that can serve as a guide or framework for all teachers who need clear insights and sensible directions. The method used by the researcher is simply narrationdescription where he presented his heartfelt and life-relating experiences to the target readers and researchers. To support his claims, he intentionally inserted real-life experiences, observations, and testimonials of teachers and personnel whom he met in his academic journeys. From the thoughts of the author-researcher, it is hoped that readers would be get inspired whenever they fell down and stressed because this essay would remind all who are engaged in teaching that the one of the best professions (if not the best) in the world is being a teacher. Other careers are not possible without the caring and guiding hands of the teachers.
\end{abstract}

Keywords: diversity, learning domains, strategies globalization, millennials, instructional

\section{INTRODUCTION}

Who is not aware of the three domains of learning? In college days, psychology and education students are oriented with cognitive, psychomotor, and affective domains which are the areas to be developed by learners. Teachers have to be creative and analytic in designing their learning plans, making sure the three major areas are emphasized. At present, how can we reconcile the three areas in our day to day meeting with our students? What type of instructional leadership among schools fits the challenges of today's world?

Violence and feud are perennially aired by media. Globalization made it easier for peoples to exchange ideas and communicate. However, the ill effects of technology harmed and destroyed lives in many parts of the world. Good news seems to be aired very seldom. People get weary and sickly from the heinous crimes reported by media. 
Will the world be filled with darkness and discord long? How can leadership in schools change the course of events? What can teachers do in this scenario?

How can we balance the three domains? In the contemporary time, which should dominate the learning process? In $\mathrm{K}$ to 12 level, hands are the most emphasized area among the three. Learners get the chance to produce outputs through technology; the easier and faster way to do them. For quite some time there is a vast misconception among elders that intelligence is limited to memorization and passing the objective-type of test. Unknowingly, there is a theory on multiple intelligence stating that a child can be naturalist, interpersonal, linguistic, musical, mathematical, spatial, and others. Being teachers of the millenials, we should be familiar with the intelligence which students may possess. Awareness of the said intelligence can help us adjust on the students' capacity and diversities. This particular aspect can be our focal point in designing our lessons, materials, and curriculum for classroom discussion.

\section{LITERATURE REVIEW}

Teachers need to be motivated always when they are in the classroom. They should be filled with energy, enthusiasm, and a learner-centered approach. In the first week of the classes, the teacher has to establish authority and power in his class where respect and obedience will be recognized by the class members. Some students do not have the interest to listen to the teacher, and they look at lecture-discussion a boring activity.

The issue of leadership for school improvement is now high on the research and policy agenda of many countries. With some inevitability, thinking about leadership has tended to focus on head teachers and how they exercise leadership. There remains a prominent belief in the leadership of the head teacher as the single source and direction of leadership in the school. This reinforces the "heroic view" of leadership where the skills and abilities to turn things around in a school are located in certain individuals. Sergiovanni (2001) notes:

It remains that the superhero images of leadership do not work. And it remains that mandates and incentives are not powerful enough to function as engines that will drive our efforts to improve schools. In tomorrow's world, success will depend upon the ability of leaders to harness the capacity of locals, to enhance sense and meaning and to build communities of responsibility.

However, research has shown that the commonly held view concerning the effects of head teacher leadership on school outcomes is not warranted. Hallinger and Heck (1996) found that the head teacher effect is small and that most effects on students were indirect. This led to the recommendation "that more attention should be given to school conditions through which such leadership flowed" (Leithwood \& Jantzi, 2000).

Fullan (2001) suggests that leaders lead from the center of a complex myriad of human relationships. Their leadership is dependent upon others and the relationships they have with others. In a learning organization, leaders may start by pursuing their own vision, but as they listen carefully to others they begin to see that their personal vision is part of something larger. This does not diminish any leader's sense of responsibility for the vision - if anything, it deepens it.

While the research evidence concerning school improvement and the school effectiveness has highlighted the importance of the leadership of the head teacher, for the most part, neither field has concentrated intensively on issues of leadership. There 
has been a consistent view emerging from the research based on effective schools that professional leadership is an important factor. Yet, how this form of leadership is developed and practiced is an underdeveloped area (Harris, et al., 2003).

There are, of course, many needed changes in schools beyond the adoption of specific innovations. The same change strategies used to address teachers' stages of concern about innovation can be used to bring about change related to any of the five tasks of supervision. A change strategy for a group of teachers who have little experience working with each other and are characterized by low levels of development, expertise, and commitment would be persuasive. Direct assistance would be furnished by directive informational interpersonal behavior by the supervisor.

A change strategy for a group of teachers who have worked together and possess moderate or mixed degrees of development, expertise, and commitment would be a reeducative strategy. Direct assistance would be provided via collaborative supervisory interpersonal skills. Professional development would emphasize the integration of learning with classroom or school-wide practice, observation, and peer assistance.

A change strategy for an experienced faculty characterized by high levels of developmental, expertise, and commitment would be facilitative. Direct assistance would be given through non-directive interpersonal behaviors of the supervisor. Group development would be approached by a supervisor as encouraging teachers to participate as the group made its own decisions.

A supervisor uses his or her own knowledge about the self, characteristics of faculty, and skills for planning supervisory tasks to determine the change strategy to use. There exists no scientific precision or algorithm for determining a faculty's level of development, expertise, and commitment.

With these change strategies, one can see how moving from persuasive to facilitative strategies moves the locus of control for the plan of action from the change agent to the target group. A persuasive strategy is a plan by the agent that depends on the group's willingness to follow. A re-educative strategy gives the target group control gives complete control to the group to plan, with the agent assisting in the implementation.

Teaching has traditionally been associated with the idea that can be disseminated through the agency of the teacher. But in late modernity, the idea that there is a truth or an indisputable theory to be taught is now harder to accept, although there are many people who still hold to the idea that what they are taught is true. Foucault in Sheridan (1980) called this a "will truth". Even so, the fact that there are a variety of teaching methods - didactic, Socratic, and facilitative - indicates that teachers have recognized that there are an increasing variety of ways of approaching their task. Nevertheless, this provides teaching with a degree of flexibility that might have become increasingly utilized in the face of the epistemological changes.

Over the years, however, there has always been the recognition that some teachings are teacher-centered and some are student-centered, although the latter has not been practiced in all forms well-marked in the education of adults, even in traditional adult education a great deal of the teaching has been didactic. By contrast, studentcentered methods presage the learners and their learning and appear more relevant to the idea of the learning society. This is also closer to the idea about education that emerged in the education of adults since one of the major differences between the education of children and that of adults is that children tend to be more dependent than adults on their teachers. Children might, but not necessarily will, be more inclined to accept what 
teachers tell them, so giving it something akin to the status of truth, while the content of the lessons of teachers of older learners may not be given such status.

Teaching methods are frequently taught in courses preparing teachers for both school and adult education, but less frequently is reference made to teaching style. Indeed, several books on teaching in higher education do not refer to teaching styles at all and even the number of the different teaching methods discussed is restricted (Brown \& Atkins, 1988).

Teaching style can motivate and influence our classroom learners as well as how we deliver the lessons and apply the activities. Even so, there is sometimes a tendency to confuse the teaching method and teaching style and merge them into a single phenomenon (Entwistle, 1981).

Methods focus on the techniques that teachers employ; they are ways of doing it processes, techniques. There is a sense in which the word "style" also refers to the way that things are done - its design and so on. Indeed, "style" is a much more difficult word to define but it is used here in relation to the manner of "expression" rather than the actual process of doing. Conti (1990) refers to this in terms of the "distinct qualities" displayed by a teacher. There is a sense in which the teacher's style helps determine the ethos, or the culture, of the situation in which the teaching takes place, although it must be recognized that as individual classes are situated in a school, college or university this also contributes to the ethos.

The distinction drawn between method and style is important here since teaching methods are about the science of teaching whereas teaching styles are about the art of teaching. Teaching methods are about the technical processes of teaching while teaching styles are more about the teachers and the way they conduct themselves during the teaching session, although Morrison and McIntyre (1973) point out that personality tests have not been useful in predicting the way that teachers actually teach.

Naturally, there is considerable overlap between style and method, since it is the same teacher who usually decides on the methods and who then conducts the teaching process, both of which contribute to the experience that learners have and from which they learn.

\section{Teaching Methods}

The self-evidence of the teaching methods assumed that either teacher would be didactic or that they would use the most efficient methods to achieve their specified objectives. Teaching involved the transmission of knowledge/theory or the teaching of skill - it was an instrumentally rational activity, the outcomes could be measured and the techniques employed could be assessed. This is the science of teaching. Underlying it are certain enlightenment values - rationality, empirical measurement, universalism, and the preeducation, more wide-ranging discussion occurred about the different types of technique, although many of these were still basically didactic. All teachers need to prepare their lessons diligently, and systems certainly help - it was the almost universalistic assumptions underlying this movement that correct preparation would achieve the desired outcomes that are more questionable.

A scientific approach to teaching and the wise use of different teaching methods are important factors in teaching, despite all of the above criticisms. Teaching is still, in part, a technical process. Teachers are demonstrating excellence in teaching when they can employ a variety of methods and techniques in the classroom settings. Even other areas of specialization can try varied tasks and methods that will fit to the kind of 
learners they have in the classroom. This has relation to the ability of the teacher to adapt and modify his teaching repertoire. But, as every teacher knows, two teachers using the same techniques to teach the same student will frequently do so in entirely different ways and the outcomes of their lesson will not be the same.

\section{Teaching Styles}

In the light of the criticisms of the scientific approach to teaching raised above, there is a certain irony that Conti's (1990) discussion on identifying teaching styles focuses upon a quantitative approach to measuring style, based upon the respondents' philosophy of teaching reflected in a Likert-type self-evaluation questionnaire. There is an assumption that if we can measure the teacher's philosophy, personality and so on, we can know something about their teaching style. Indeed, Eble (1988) has suggested that "style is the image of the character". But Morrison and McIntyre (1973) have argued that there does not seem to be a relationship between personality tests and the approach to teaching that different teachers assume. Yet, teaching is still about helping others learn, a process in which teachers as individuals still play an important role - but play the role they do, for teaching is an art form, as well, a science. Each teacher has his unique philosophy and perspective that can guide him in achieving his sets of goals. From his own experience, he can enhance his capacity to teach.

Fundamentally, the character of the teacher plays a fundamental role in teaching teachers themselves are their best teaching aids. Emphasis on teaching methods tends to standardize teaching but the emphasis on style highlights the individuality of teachers and allows for the recognition that every class is a unique event, with the teachers alone being the common element in the different classes that they teach. However, teaching is both an art and a science and so we can combine the two approaches: we can have authoritarian facilitators and democratic didactics, as well as, authoritarian didacticism and democratic facilitators. Teachers can be friendly but didactic or friendly but Socratic, and so on. There is no limit to the combinations that can be put together - each class is a unique event: this is what the task of teaching is all about. But it is no easy role, as those of us who do it know only too well, for our teaching style also makes demands on us individuals, as Parker (1998) beautifully illustrates.

Teaching methods and teaching styles reflect the art and science of teaching; they reflect the modern age of science but point beyond it to the validity of the art, the performance and the reality of the uniqueness and humanity of teaching. To try to restrict teaching to its methods is to fail to understand the teaching and learning process; to try to restrict it to its art allows for the possibility of irresponsibility and unacceptable eccentricities. To understand the relationship of the one to the other is extremely difficult since each of us who teaches engages not only in a time-honored process but one that is quite unique to the occasion when we are teaching. The more we understand ourselves, the more likely we are to understand those whom we are privileged to teach. In the process of teaching and learning, style is as important, if not more important, than method (Jarvis, 2002).

Teaching is a challenging profession. There are skills and knowledge needed by the teacher to deliver quality lessons and activities. Having a mastery of the subject matter and educational qualification may not be enough to ensure effective instruction. One of the requirements to achieve balanced and quality instruction is classroom management. 
On the first day of the class, the language teacher usually explains his sets of rules and policies to his students. He discusses the dos and don'ts that students have to religiously follow. He goes into details on how learners could properly meet the expectations of the teacher and how they should behave in the class. Moreover, the teacher needs to explain the grading system and the learning assessment tools he will employ in gauging the performances of the class. It is imperative that the teacher involves all students in the construction and validation of the classroom rules and policies so that students will feel that they are informed or oriented in the formulation of such rules.

While the teacher serves as a classroom model and manager in the class, he has to be selective and judicious in using the methods and techniques appropriate to the capacity and experience of the learners. Making wise decisions on how students would behave and act in the class should be handled by the flexible and reflective language teacher. This is however not an easy task because the teacher himself should be armed with sound principles and relevant ideas he needs to maintain and sustain classroom management. If issues and problems arise in the classroom, the teacher can always talk with is class officers and explain how all of these could be fixed reasonably and fairly without offending or humiliating members of the class. The organized classroom is controlled by the dynamic and wise teacher who is always ready to face all the challenges and changes in the class.

Being a teacher in the $21^{\text {st }}$-century education is a big challenge. It is not enough that language teachers have the knowledge and concepts to teach. They also need perspectives, insights, and practices that agree with the demands of modern society. Teachers are flexible and adaptive to changes. They can improve themselves to cater to the needs of the global learners. They can actually use technology in making the lessons and ideas absorbed by the Millenials.

Instructional leadership is imperative in the classroom learning and teaching as implied by the situations and contexts from the reviewed materials. Based on the literature and studies cited and synthesized by the researcher, it is a crystal clear fact that language teachers have to be open to new ideas and responsive to the trials and predicaments seen in the classroom. True to say that there is no perfect organization as there is no perfect teacher. But with a sincere heart and open mind, the language teacher can chase possibilities and assimilate great ideas to improve himself and others. The modern education nowadays is characterized by technology, innovation, and computer. With the many seminars, forums, and conferences offered by various agencies and organizations, there is no way that the teacher would be left. He can grab the chance of becoming a better version of himself as he participates in meaningful and insightful events and activities.

\section{DISCUSSION}

This society has reached the peak of global industrialization and innovation in which the needs of people are quickly fed by technology. In the literal sense, people can feel and see advancement around the world. The fast-changing environment led us to quick access to information. We get a picture of what happens around us by just a click on the computer. We are clothed and fed with foreign ideas because they come to us the easiest and fastest way they can with the aid of information technology. People do not care about the possible hazards of technology since they are only after what can give them convenience and security. During these changes, what would be the key role being 
played by educational leaders? What kind of education programs should academic institutions design? While we observe what is happening around us, we educators can conduct academic discussions with stakeholders on how we could adapt the education of the twenty-first century. How can we foster and reinforce the minds of $21^{\text {st }}$-century learners? How can we neutralize cognitive, psychomotor, and affective domains of learners using multifarious tasks and relevant lessons? Should there be a paradigm shift so that we can weigh things properly and appropriately?

Let us face it. Gone are the days when we rely only on traditional pedagogies in teaching our students. Nowadays, everything that a child wants to know can be obtained through technology that is the use of a laptop, smartphone, iPod, tablets, etc. we struggle in moving our students away from the interruptions of these gadgets. But come to think of it; we can, in fact, use these tools to make our students updated and oriented on the various information they can get and apply in their academic life. Even if they depend too much on technology, we can always give them intervening activities that will make their learning focus not only on the competencies and knowledge they need but also on attitude. Now that we are in an innovative dimension, we have to upgrade ourselves with the functions of technology. In that we way, we can adjust to the needs of our learners. We can design appropriate instructional materials that can facilitate effective instruction among our students.

In the foregoing discussion, what type of educational structure should educational and instructional leaders formulate? I believe the future structure of education should provide balance pacing among the three major components of a lesson, cognitive, psychomotor, and affective. What intervening programs can we offer to our teachers to enhance or improve their performance while they deliver quality lessons to their students? Where should be our starting point? Can we harmonize all elements so that students can still sustain and maintain pleasing values they can wear while they are in the workplace? Imagine what and how this world would be when we have clever, skillful, and passionate workers. They will work because of their desire to serve others and show the potentials they possess. They will work not due to the competition but for cooperation and respect. And when they epitomize the said traits, I am sure this world will be a wonderful place to live in. Each day, educators have high hopes for this country. Through their head, hands, and heart, I am sure they can cultivate and nurture future builders of this country who would complete a society of mind, heart, and hands.

Teachers provide the light to the youth which they need to follow towards their success in life. Their task is not a piece of cake due to abundant challenges and predicaments that come their way. In the contemporary time, teachers are steadfast and resourceful because their endurance has been tested by time and change. They grow indeed wherever they go and whomever they meet along the way. In teacher development, the government should allot funds to assist all teachers from various areas in the country. There should be assistance for education, training, and health concerns. I am certain that if teachers are properly honed, they would become more productive, motivated, and dynamic in the delivery of quality education. We have to bear in mind that the foundation of the future is built by teachers. Careers of the world would not come to existence if teachers were not born. They paint the sceneries and pictures of the world through their creative and influential hands. They possess mind, heart, and hands in creating jobs and careers that sustain the needs of people. The world is full of possibilities when students are nurtured and harnessed by our dear teachers. This part 
implies that teachers design the academic structure of the future. Educational environment and the conditions of learners are brought to life by teachers.

While writing this article, the writer wishes to see a progressive country in the near future. He has the vision of seeing productive, assertive, and resilient citizens who are always ready to give their best and selflessly offer their strength in lifting the country to reach heights of success. Dreaming a picture is attainable when you as a leader will spearhead your vision. In your small way, you can help. When you do your duty of teaching students with values, skills, and knowledge, you are guiding them towards achieving their dreams. Nothing is impossible when we hope for the best!

With all the effects of globalization and popular culture, I cannot help but reflect on how teachers should work in the future. Should they be totally different from the ones we have today? When changes come, should they also change? What emerging issues in teacher education, curriculum, and pedagogy would affect the teachinglearning process? We cannot dwell in the past using old pedagogies and practices. We have to connect our talents, skills, and values to what is actually occurring around the world. In this way, we can have efficient and effective ways to teach the learners and provide a difference in their lives. The varied and meaningful plans we have for the students should always be congruent to the goals we have set.

\section{CONCLUSIONS AND SUGGESTIONS}

We, as teachers, should explore. Let us retool our pedagogies and cultivate the potentials we have as educators. While we sharpen our horizon and cultivate our skill, we should also show compassion, mercy, and love to others. This is achieved if only we have concern for others. We serve as inspiration and motivation for our students and colleagues to do their best and follow what we have set. Each day can be meaningful when we have a sincere and blissful heart to teach others. We can make a difference to all who sit and listen in our class. It is we who can change the landscape of the educational system because we are the front liners in the battlefield.

We give hope to the hopeless; we give sight to those who are blinded by sins; we give words to those who are muted by threat; and we give shelter to those who are lost and misled. Teachers are the ones who complete this society, and without them, tomorrow seems to be dim. Teachers guide people in forming their thoughts and finding their places.

\section{REFERENCES}

Conti, G. J. (1990). Identifying your teaching style, in Adult learning methods, Ed M W Galbraigth, Robert Krieger, Malabar.

Eble, K.E. (1988). The craft of teaching, $2^{\text {nd }}$ Edition, Jossey-Bass, San Francisco, CA.

Entwistle, N. (1981). Styles of learning and teaching, John Wiley, Chichester.

Fullan, M. (2001). Leading in a culture of change, San Francisco, Jossey-Bass.

Hallinger, P. and Heck, R.H. (1996). "The Principal's Role in School Effectiveness: An Assessment of Substantive Findings", paper presented at AERA Annual Conference, New York.

Harris, A., Day, C., Hopkins, D., Hadfield, M., Hargreaves, A., and Chapman, C. (2003). Effective leadership for school improvement. London and New York: RoutledgeFalmer, Taylor and Francis Group.

Jarvis, Peter. (2002). The theory and practice of teaching. USA. Stylus Publishing Inc. 
Leithwood, K. and Jantzi, D. (2000). "Transformational Leadership: How Principals Can Help Reform Cultures", School effectiveness and school improvement.

Marzano, Jana S. and Pickering, Debra J. (2003). Classroom management that works: Research-based strategies for every teacher. Association for Supervision and Curriculum Development, Alexandria, Virginia, USA.

Morrison, A. and McIntyre, D. (1973). Teachers and teaching, $2^{\text {nd }}$ Edition, Penguin, Harmondsworth.

Parker, P.J. (1998). The courage to teach, Jossey-Bass, San Francisco, CA.

Sergiovanni (2001). Leadership: What's in for schools, London, RoutledgeFalmer.

Sheridan, A. (1980). Michael Foucault: The will to truth, Tavistock, London. 